\title{
Measurement of the Innovation Efficiency of the Hi-tech Industry in China and Its Influencing Factors
}

\author{
Sufen Han*, Hongyu Liu, Yan Lin \\ Science and Technology Finance Key Laboratory, Hebei University of Finance, Baoding 071051, China
}

Corresponding Author Email: zxbhan@126.com

https://doi.org/10.18280/ijsdp.150303

Received: 18 September 2019

Accepted: 25 December 2019

\section{Keywords:}

China, innovation efficiency of the hi-tech industry, influencing factor, CCR model

\begin{abstract}
Accelerating the development of the hi-tech industry is a key measure to effectively implement the "Made in China 2025" strategy. In order to measure the innovation efficiency of the hitech industry, this paper establishes an evaluation index system for the innovation input and output of the hi-tech industry. Then, based on the data of the input and output variables collected, this paper uses the CCR model to measure the innovation efficiency of the hi-tech industry in 30 provinces and municipalities of China during the period of 2002-2016. At the same time, it investigates the spatial correlation of the innovation efficiency of the hi-tech industry, and empirically analyzes the influencing factors to the innovation efficiency of the hi-tech industry using a spatial measurement model. According to the results of this study, the innovation efficiency of the hi-tech industry exhibit significant provincial differences. The provinces and municipalities where the hi-tech industry is of high innovation efficiency are mainly located in the eastern coastal areas, while the innovation efficiency of the hi-tech industry in those most mid-western inland provinces and municipalities is less than satisfactory. In this paper, China is divided into three major regions - East China, Central China and West China. It is found that the innovation efficiency of the hi-tech industry in these three regions showed basically the same trend during the sample period, but with serious regional differentiation - the innovation efficiency of the hi-tech industry was the highest in the east, the second highest in the central region, and the lowest in the west. The global Moran's I index was all positive during the sample period and passed the significance level test, indicating that the innovation efficiency of the hi-tech industry in China has significant spatial correlation. The spatial LISA chart shows that the innovation efficiency of the hi-tech industry in most provinces and municipalities is located in the spatially clustered quadrants, while that in only a few provinces and municipalities is located in the spatially scattered quadrants. The results of the spatial measurement model shows that the R\&D intensity, opening-up and human capital have positive effects in promoting the innovation efficiency of the hi-tech industry, that government intervention clearly hinders the improvement of the innovation efficiency and that enterprise size and industrial structure exhibit no significant effects.
\end{abstract}

\section{INTRODUCTION}

In recent years, China put forward the "Made in China 2025" strategy, clearly stating its focus on improving the quality and level of the manufacturing industry in an all-round way. To achieve this goal, one of the key measures is to further accelerate the development of the hi-tech industry. As an important part of the entire industrial system in China, the hitech industry not only serves as an important carrier for technological innovation, but also plays an essential role in optimizing the industrial structure. Along with the new round of scientific and technological revolution, the focus of the hitech industry development is shifting from quantity accumulation to quality improvement. Therefore, innovation is playing an increasingly important role in accelerating the development of the hi-tech industry. In recent years, however, with the changes in China's macroeconomic environment, plus some deficiencies in the development process, the development momentum of the hi-tech industry has slowed down. In particular, the hi-tech industry in China has long been struggling with the problem of "high input, low output"; in other words, the overall innovation efficiency is not satisfactory. In this context, how to effectively improve the innovation efficiency of the hi-tech industry under the "new normal" of economic development has become an important research topic, as it directly concerns which direction the supply-side reform of the Chinese hi-tech industry will turn to in the future. Regarding this, a number of questions have been raised, such as which is the current innovation efficiency of the hi-tech industry in different provinces and municipalities in China? And what factors are influencing the innovation efficiency of the hi-tech industry? Finding the answers to these questions is essential for accelerating the development of the hi-tech industry in this country.

There are a lot of research on the innovation efficiency of the hi-tech industry, but most of them are focused on the following three aspects. The first is the establishment of an evaluation index system for the innovation efficiency of the 
hi-tech industry. There are two types of research on this: one is using a single indicator, such as the patent output of the hitech industry [1]; and the other is using an index system, consisting of commonly used evaluation indices in the academic community, such as composite indices [2, 3] and input and output indices [4-6]. The second is the evaluation method for the innovation efficiency of the hi-tech industry. There are two mainstream evaluation methods - SFA and DEA For example, Hong et al. [7] applied SFA to measure the innovation efficiency of the hi-tech industry in China. Compared with SFA, DEA is more widely applied in the evaluation on the innovation efficiency of the hi-tech industry. Hsiao and Park [8], Han et al. [9] and Chen et al. [10] used DEA to evaluate the innovation efficiency of the hi-tech industry. The third is the influencing factors to the innovation efficiency of the hi-tech industry. Existing research shows that R\&D investment [11], government support [12], technological absorptive capacity [13], FDI [14] and human resources [15], etc. are all important factors that can influence the innovation efficiency of the hi-tech industry.

Although evaluating the innovation efficiency of the hi-tech industry and exploring the influencing factors thereto has already become a hotspot for scholars at home and abroad, there is still a serious deficiency in the existing research, that is, most scholars have overlooked the spatial correlation between regions in terms of innovation efficiency when exploring the innovation activities of the hi-tech industry. With the economic integration continues to deepen and the exchanges of scientific and technological resources increasing among regions, the spatial correlation between regional innovation activities is getting increasingly stronger. In view of this, ignoring spatial correlation in the study of the innovation activities in the hi-tech industry may lead to significant deviations in the research results. Therefore, to further improve the accuracy of the study, this paper evaluates the innovation efficiency of the hi-tech industry in various provinces and municipalities in China by the DEA method, analyzes its spatial correlation and establishes a spatial measurement model to investigate the influencing factors to the innovation efficiency of the hi-tech industry.

\section{MATERIALS AND METHODS}

\subsection{CCR model}

Generally speaking, there are currently two main methods for measuring efficiency, namely DEA and SFA. When used to evaluate the efficiency measured by the input and output indices, SFA needs to construct the form of the equation, and it can only deal with a single output. In comparison, DEA can deal with multiple inputs and multiple outputs. Not only is it more flexible, but it also requires smaller sample size. All these advantages make it unmatched by SFA. In view of this, this paper finally uses DEA to measure the innovation efficiency of the hi-tech industry. DEA, short for data envelope analysis, is a typical non-parametric analysis method, built on the idea of linear programming. The principle is that, suppose there is an evaluation index system, where the input and output indices constitute multiple decision making units (DMUs), then among all the DMUs, the one located on the production frontier found by the linear programming method is the optimal DMU, while the others that deviate from the production frontier are non-optimal DMUs This shows that the efficiency value of each DMU measured by DEA is relative efficiency.

Chames et al. [16] proposed the CCR model, the first model of DEA, which can process the multiple inputs and outputs in the production sector, and its results can be used to determine whether the production sector has reached technical efficiency and scale efficiency. It can be said that among the many DEA models, the CCR model can effectively evaluate the relative efficiency of multiple inputs and outputs in the production sector, and thus it is widely applied in the economic, environmental and other fields.

The specific operating principle of the CCR model is as follows: suppose that there is a production system containing n DMUs, among which the $\mathrm{j}$-th DMU is denoted as $D M U_{j}(1 \leq$ $j \leq n) . x_{j}$ is the input element required by the DMU, and $y_{j}$ is the output result of the DMU, and there is $x_{j}>0$ and $y_{j}>0$. Then, the input elements and output results of the DMUs in the entire production system are expressed as follows:

$$
\left\{\begin{array}{l}
X_{j}=\left(x_{1 j}, x_{2 j}, x_{3 j} \cdots x_{m j}\right)^{T} \\
Y_{j}=\left(y_{1 j}, y_{2 j}, y_{3 j} \cdots y_{m j}\right)^{T}
\end{array}, 1 \leq j \leq n\right.
$$

In the calculation process of all DMUs that constitute the entire production system, the input elements and output results of each DMU need to be given certain weights. Suppose the weight vector of the input elements of a DMU is $v=$ $\left(v_{1}, v_{2}, v_{3} \cdots v_{m}\right)^{T}$, and that of the output results is $v=$ $\left(v_{1}, v_{2}, v_{3} \cdots v_{m}\right)^{T}$. Then, with the formula $h_{i}=u^{T} Y_{i} / v^{T} X_{i} \leq$ 1 , the relative efficiency of each DMU can be evaluated. Under the premise that $1 \leq j \leq n$ is satisfied, the efficiency function $h_{j 0}(1 \leq j \leq n)$ is the goal that the optimal DMU can achieve, which means that the DMU should be on the production frontier at this time. Based on this, the basic expressions of the CCR model are as follows:

$$
\left\{\begin{array}{l}
\max \frac{u^{T} Y_{0}}{v^{T} X_{0}}=0, \\
\text { s.t. } h_{j}=\frac{u^{T} Y_{j}}{v^{T} X_{j}} \leq 0,1 \leq j \leq n \\
u \geq 0, u \geq 0, \\
X_{0}=X_{j 0}, Y_{0}=Y_{j 0}, 1 \leq j \leq n
\end{array}\right.
$$

\subsection{Evaluation index system}

The innovation efficiency of the hi-tech industry (denoted as $I E$ ) studied in this paper is the technical efficiency of the hitech industry, which can be explained from two perspectives. From the perspective output, it is the ratio between the actual output of innovation in the hi-tech industry and the optimal one when the input elements of innovation in the hi-tech industry are constant. The ratio ranges from 0 to 1 . The larger the ratio, the smaller the gap between the actual output of innovation in the hi-tech industry innovation and the optimal one, that is, the higher the efficiency value; conversely, the smaller the ratio, the lower the efficiency value. From the perspective of input, the innovation efficiency of the hi-tech industry refers to the ratio between the ideal minimum input and the actual input of innovation elements. The larger the ratio, the smaller the gap between the ideal minimum input and the actual input of innovation elements, that is, the higher the efficiency value; conversely, the smaller the ratio, the lower 
the efficiency value. In summary, the high innovation efficiency of the hi-tech industry referenced in this paper means the innovation output reaches the maximum level when the input elements are constant, or that the minimum amount of innovation input elements is required when the output is given.

Based on the research results of Qian et al. [17] and Gui [18] and considering the principles of comprehensiveness, scientificity and operability, this paper establishes an inputoutput evaluation index system for the innovation efficiency of the hi-tech industry. The whole evaluation index system consists of two input indices - capital and manpower and two output indices - patent and new product sales revenue. The meaning of each index is given below:

(1) Capital input: By reference to the research results of Sun et al. [19], this paper uses two indices - internal R\&D cost and new product development cost - to represent capital input. The internal R\&D cost of the hi-tech industry reflects the sum of the direct and indirect costs incurred by the hi-tech industry to support R\&D activities, which is an effective indicator of how much capital is input in the internal $R \& D$ activities in the hi-tech industry. Considering that costs are inevitably affected by inflation, to ensure the accuracy of the evaluation results, this paper deflates the nominal internal $R \& D$ cost in the hitech industry to the actual value using the $2002 \mathrm{R} \& \mathrm{D}$ price index given by $\mathrm{Zhu}$ and $\mathrm{Xu}$ [20] as the base-period index. What is more, innovation in the hi-tech industry is a highly persistent R\&D activity, which means it is affected by not only the current $R \& D$ capital input, but also the past capital input. Therefore, this paper needs to convert the internal $R \& D$ cost from a flow indicator to a stock indicator. By reference to the research result of Coe and Helpman [21], which is the perpetual inventory method, this paper converts the internal R\&D costs of previous years from flow data to stock data using the formula $R D S_{i, t}=(1-\delta) R D S_{i, t-1}+R D F_{i, t}$, where $R D S_{i, t}$ means the stock of the internal R\&D cost, $R D F_{i, t}$ means the flow of the internal R\&D cost, and $\delta$ is the depreciation rate, which is set to $15 \%$. In addition, the innovation activities in the hi-tech industry are also supported by new product development cost, especially during the transformation of technological achievements, where how much is spent on new product development directly determines the market competitiveness of the innovative product. Also by the price deflation method and the "perpetual inventory method", this paper converts the flow data of the new product development costs in the hi-tech industry over the years into stock data with 2002 as the base period.

(2) Manpower input: In addition to capital, manpower is also an important element of the innovation activities in the hitech industry [22]. Only by effectively combining R\&D capital and manpower can the entire innovation activities be carried out successfully. In view of this, this paper adopts the full-time equivalent of the innovation R\&D personnel in the hi-tech industry as the index of manpower input in the process of innovation activities. Compared with the number of R\&D personnel, full-time equivalent is more comprehensive and reasonable as a manpower index, as it includes not only the number of full-time personnel engaged in the innovation activities, but also the number of part-time personnel.

(3) Output indices: By reference to the research result of Zhuang et al. [23], this paper uses the number of patents applied for and the sales revenue of new products in the hitech industry to characterize the output. Patents are the direct embodiment of new technologies, ideas and processes, so the number of patents applied for reflects the specific output of the innovation activities in the hi-tech industry. How big this number is often showing the R\&D capability of the hi-tech industry. The sales revenue of new products reflects the economic benefits brought by the transformation of innovation achievements. It is an important manifestation of how well the innovation achievements are integrated with the market. Further, it is the best indicator that manifests the value of innovative activities in the hi-tech industry. Similarly, in order to prevent monetary inflation from distorting the sales revenue of new products, this paper deflates the nominal sales revenue of new products in the hi-tech industry over the years to the actual values using the ex-factory price index of industrial products with 2002 as the base period

In summary, the evaluation index system for the innovation efficiency of the hi-tech industry constructed in this paper consists of two categories of indices - input and output indices. Input indices are composed of capital input and manpower input, while output indices are the number of patents applied for and the sales revenue of new products. After serious consideration, this paper finally establishes the evaluation index system for the innovation efficiency of the hi-tech industry with 5 specific indices (see Table 1).

Table 1. Evaluation index system for the innovation efficiency of the hi-tech industry

\begin{tabular}{|c|c|c|c|}
\hline $\begin{array}{c}\text { Index } \\
\text { level }\end{array}$ & $\begin{array}{c}\text { Level } 1 \\
\text { index }\end{array}$ & $\begin{array}{c}\text { Level } 2 \\
\text { index }\end{array}$ & Unit \\
\hline \multirow[t]{2}{*}{$\begin{array}{l}\text { Input } \\
\text { indices }\end{array}$} & Capital input & $\begin{array}{c}\text { Internal R\&D cost } \\
\text { New product } \\
\text { development cost }\end{array}$ & $\begin{array}{c}10,000 \\
\text { Yuan RMB } \\
10,000 \\
\text { Yuan RMB }\end{array}$ \\
\hline & $\begin{array}{l}\text { Manpower } \\
\text { input }\end{array}$ & $\begin{array}{l}\text { R\&D personnel full- } \\
\text { time equivalent }\end{array}$ & Persons \\
\hline \multirow{2}{*}{$\begin{array}{l}\text { Output } \\
\text { indices }\end{array}$} & Patent output & $\begin{array}{l}\text { Number of patents } \\
\text { applied for }\end{array}$ & Each \\
\hline & $\begin{array}{c}\text { Economic } \\
\text { output }\end{array}$ & $\begin{array}{l}\text { Sales revenue of new } \\
\text { products }\end{array}$ & $\begin{array}{c}10,000 \\
\text { Yuan RMB }\end{array}$ \\
\hline
\end{tabular}

\subsection{Spatial autocorrelation coefficient and spatial LISA chart}

According to Tobler's First Law of Geography [24], the relation between things has a lot to do with their spatial distances, and the two show a typical inverse relationship. As a key development industry in China, the hi-tech industry carries out frequent innovation activities and exhibits a strong spatial association between regions. Such spatial association, also known as spatial correlation, is specifically composed of spatial agglomeration and spatial heterogeneity. Spatial agglomeration refers to the spatial spillover and diffusion effects exhibited by the innovation activities in regional hitech industry. Generally speaking, the closer the distance between the regions, the stronger the spatial agglomeration effect. Spatial heterogeneity means that due to the existence of spatial non-uniformity, there are differences between the innovation activities in the central area and the marginal area, which leads to the spatial dispersion of innovation activities in the hi-tech industry. Generally speaking, the index that measures the magnitude of this spatial correlation is the Moran's I index. Moran [25] was the first to propose the global Moran's I index, whose specific expression formula is as follows: 


$$
\text { Moran's } I=\frac{n}{\sum_{i=1}^{n}\left(x_{i}-\bar{x}\right)^{2}} \frac{\sum_{i=1}^{n} \sum_{j=1}^{n} W_{i j}\left(x_{i}-\bar{x}\right)\left(x_{j}-\bar{x}\right)}{\sum_{i=1}^{n} \sum_{j=1}^{n} W_{i j}}
$$

In formula (3), the Moran's $I$ index represents the spatial correlation of the observed values in $\mathrm{n}$ regions, where $x_{i}$ represents the observed value of region $i$, and $x_{j}$ is the observed value of region $j . \bar{x}=\left(\sum_{i} x_{i}\right) / n$ is the mean of the observed values in all regions in the formula. $W_{i j}$ is the spatial weight matrix incorporated in the formula, which usually consists of 0 and 1, arranged in the matrix form. After all observed values are input into special software, the global Moran's $I$ index is obtained. The value of the global Moran's I index is within the range of [-1 1], that is, with a lower limit of -1 and an upper limit of 1 . If the measured global Moran's $I$ index is equivalent to -1 , i.e. the lower limit, it indicates that the observed values have perfect negative spatial correlation; if the measured index is equivalent to 1, i.e., the upper limit, it means that all observed values have perfect positive spatial correlation; and only when Moran's $I=0$, there is no spatial correlation at all between the observed values.

After the specific value the global Moran's $I$ index is measured, whether it is authentic or not still needs to be tested for its significance. This paper uses the traditional Z-score normal distribution method to verify the significance of the Moran's $I$ index. There are three critical values $-10 \%, 5 \%$ and $1 \%$ - to measure the significance level. If the Z-score normal distribution test results pass these three critical values, it means that the Moran's I index is authentic. The expression of Z-score is as follows:

$$
Z(d)=\frac{[\text { Moran's I-E }(\text { Moran's I })]}{\sqrt{\operatorname{VAR}(\text { Moran's } I)}}
$$

If we use the global Moran's I index alone to measure the spatial correlation of the observed values, we can only analyze the global spatial characteristics and cannot effectively study the spatial correlation within the observed values. In order to further analyze the spatial properties of the observed values in the local space, this paper further introduces the local Moran's $I$ index in the study. The local Moran's I index is also called the local scatter plot (LISA), which depicts the specific distributions of the observed values in the four quadrants $(\mathrm{H}-$ $\mathrm{H}, \mathrm{L}-\mathrm{H}, \mathrm{L}-\mathrm{L}$ and $\mathrm{H}-\mathrm{L}$ ) of the spatial coordinate chart. In the spatial LISA chart, the spatial properties of the observed values are clearly shown. According to the research result of Moran [26], the formula of the local Moran's I index is as follows:

$$
\text { Moran's } I=\frac{n^{2}}{\sum_{i=1}^{n}\left(x_{i}-\bar{x}\right)^{2}} \frac{\left(x_{i}-\bar{x}\right) \sum_{i=1}^{n} \sum_{j=1}^{n} W_{i j}\left(x_{j}-\bar{x}\right)}{\sum_{i=1}^{n} \sum_{j=1}^{n} W_{i j}}
$$

\subsection{Spatial measurement model for the influencing factors to the innovation efficiency of the hi-tech industry}

Analyzing the influencing factors is the key to further improving the innovation efficiency of the hi-tech industry. Based on the research results of Yang and Yang [27], Wang and Degn [28], Sandu and Clocanel [29], Boeing [30] and Nonaka et al. [31], and from both the internal and external perspectives, this paper analyzes the influences of 6 factors, namely enterprise size $(E S), \mathrm{R} \& \mathrm{D}$ intensity $(R I)$, industrial structure $(I S)$, opening-up $(O P)$, government intervention $(G I)$, and human capital $(H C)$, on the innovation efficiency of the hi-tech industry. However, to perform such analysis, it is also necessary to establish an appropriate measurement model for regression analysis. When a conventional measurement model is used to analyze the influences of explanatory variables on explained variables, it is often assumed that each explanatory variable is independent of each other, that is, the model does not need to consider any spatial factor, which is obviously not in line with reality. To incorporate the spatial factor that is often ignored by conventional models, a spatial measurement model is applied in this paper to carry out regression analysis to fully improve the accuracy of model estimation. The current spatial measurement models can be divided into two basic types - spatial auto-regressive model $(S A R)$ and spatial error model $(S E M)$. Based on the basic form of $S A R$ proposed by Anselin [32], this paper builds a spatial auto-regressive model for the influences on the innovation efficiency of the hi-tech industry, with the specific expression formula provided as follows:

$$
\begin{aligned}
& I E_{i, t}=\alpha_{i}+\phi_{t}+\beta_{1} E S_{i, t}+\beta_{2} R I_{i, t}++\beta_{3} I S_{i, t}+\beta_{4} O P_{i, t} \\
& +\beta_{5} G S_{i, t}+\beta_{6} H C_{i, t}+\rho W\left(I E_{i, t}\right)+\varepsilon_{i t}
\end{aligned}
$$

where, $\rho$ is the auto-regressive coefficient in the spatial autoregressive model, used to measure the spatial effect between different regions; $W$ is the spatial weight matrix, which generally has three forms: adjacency matrix, economic matrix and distance matrix, where the adjacency matrix, due to its simple structure and wide application, is chosen in this study; and $\varepsilon_{i t}$ is the random error term in the model.

Based on the spatial error model (SEM) given by Haining [33], the expression of the $S E M$ used in this paper for the influencing factors to the innovation efficiency of the hi-tech industry is as follows:

$$
\begin{gathered}
I E_{i, t}=\alpha_{i}+\phi_{t}+\beta_{1} E S_{i, t}+\beta_{2} R I_{i, t}++\beta_{3} I S_{i, t} \\
+\beta_{4} O P_{i, t}+\beta_{5} G S_{i, t}+\beta_{6} H C_{i, t}+\varepsilon_{i t} \\
\varepsilon_{i t}=\lambda W_{2}+u, u \sim N\left(0, \sigma_{\varepsilon}^{2} I_{n}\right)
\end{gathered}
$$

In formula (7), $\lambda$ is the error coefficient in the spatial error model, whose basic form is the $n * 1$-order matrix. The value of this coefficient is a measure of the spatial correlation between the residual terms of the entire model. $u$ is the random disturbance term in the model.

In formulas (6) and (7), the specific meaning of each variable index is as follows: $I E$ is the explained variable in this paper, namely the innovation efficiency of the hi-tech industry; $E S$ is the enterprise size, characterized by the ratio between the sales revenue and the number of hi-tech enterprises in the hi-tech industry in each province or municipality; $R I$ is the R\&D intensity, represented by the ratio between the internal R\&D cost and the sales revenue of new products in the hi-tech industry in each province or municipality; IS is the industrial structure, characterized by the proportion of the output value of the secondary industry in the Gross Domestic Product (GDP) of each province or municipality; $O P$ is opening up, expressed by the ratio between the delivery value for export and the sales revenue of the hi-tech industry in each province or municipality; GI is 
government intervention, characterized by the proportion of government funds in the internal R\&D cost of the hi-tech industry; and $H C$ is human capital, expressed by the proportion of the labour force whose education level is high school or above in the total labor force in each province or municipality

\subsection{Data source}

In order to ensure the comprehensiveness and operability of the variable data in the model, this paper selects the panel data of the hi-tech industry in 30 provinces and municipalities in China from 2002 to 2016 as the object of empirical analysis. Due to serious lack of data from Tibet, Hong Kong, Macau and Taiwan during data acquisition, these regions are excluded from the data samples. Finally, the variable data of the hi-tech industry required in this paper, including the internal $R \& D$ cost, new product development cost, full-time equivalent of R\&D personnel, number of patents applied for, sales revenue of new products, sales revenue, delivery value for export and GDP, output value of the secondary industry, labour force with education level above high school and total labour force, are all obtained from the China Statistics Yearbook on High Technology Industry, China Statistical Yearbook, China Labour Statistics Yearbook and various local statistical yearbooks.

\section{RESULTS}

\subsection{Provincial differences in the innovation efficiency of the hi-tech industry in China}

Based on the constructed evaluation index system for the innovation efficiency of the hi-tech industry, this paper collects the data of the variables constituting the input and output indices, and then enter them into the software maxDEA for efficiency evaluation. The specific measurement method is the non-input-oriented CCR model in DEA, with input and output indices having equal weights. By running the software, this paper finally obtains the innovation efficiency values of the hi-tech industry in 30 provinces and municipalities in China from 2002 to 2016, as shown in Figure 1. It can be seen that the innovation efficiency of the hi-tech industry in China exhibited great provincial differences. Judged by the average innovation efficiency of the hi-tech industry in each area, the top five provinces and municipalities in the country were Tianjin, Fujian, Beijing, Hainan and Guangdong. All these five provinces and municipalities are located in the eastern coastal area, among which, Tianjin had an average efficiency of 0.9-1, Fujian and Beijing 0.8-0.9, and Hainan and Guangdong 0.7-0.8. Qinghai, Hebei, Xinjiang, Heilongjiang and Shaanxi were the bottom five provinces and municipalities, with low innovation efficiency of the hi-tech industry. Except Hebei, all the provinces are located in the mid-western inland areas of China. The average efficiency values of Qinghai, Hebei and Xinjiang were between 0.3-0.4, while those of Heilongjiang and Shaanxi were below 0.2. In short, most of the provinces and municipalities with high innovation efficiency of the hi-tech industry in China are located in the eastern coastal areas, while those with relatively low innovation efficiency are mostly located in the mid-western inland area. Therefore, the Chinese government should shift its policy focus to the provinces and municipalities in Central and West China in the future to address the unbalanced development of the hi-tech industry among provinces.

Figure 2 shows the changing trend of the innovation efficiency of the hi-tech industry throughout China and in the three major regions - East, Central and West China. Overall, the trend changes are basically the same in all these regions, that is, they all exhibited relatively drastic fluctuations during the sample period. Specifically, the trend can be divided into four distinct stages: during 2002-2004, the innovation efficiency of the hi-tech industry throughout China and in the three major regions showed a clear downward trend; during 2005-2009, it was slowly going upward; during 2010-2014, it was relatively stable without major fluctuations; and during 2015-2016, it showed an upward trend again. At the same time, the average value of the innovation efficiency of the hi-tech industry throughout China and in the three major regions showed significant regional differences. The average innovation efficiency value of the hi-tech industry in East China was 0.6987 during the sample period, higher than the national average of 0.5909 ; the average innovation efficiency values of the hi-tech industry in Central and West China were 0.5516 and 05116 , respectively, which were not much different, but both lower than the national average. In summary, the innovation efficiency of the hi-tech industry is the highest in East China, followed by that in Central China, and the lowest is in West China. This fully shows that the regional differences are significant in the development of the hi-tech industry in China. Therefore, if China plans to improve the overall quality of the hi-tech industry in the future, the central and western regions are particularly important areas of concern.

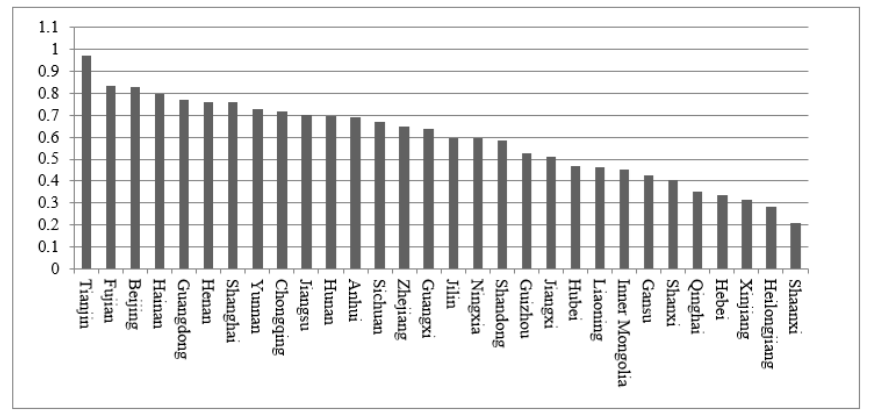

Figure 1. Average innovation efficiency of the hi-tech industry during 2002-2016 by province/municipality

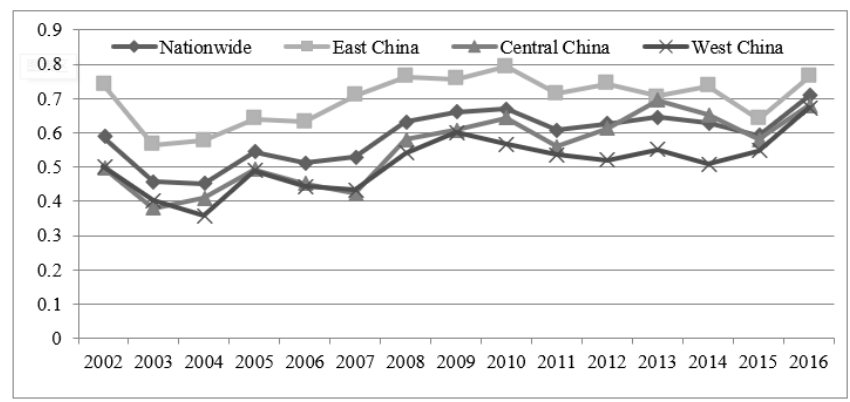

Figure 2. Changing trends of the innovation efficiency of the hi-tech industry throughout China and in the three major regions - East, Central and West China 


\subsection{Spatial correlation analysis of the innovation efficiency of the hi-tech industry in China}

This paper enters the data of the innovation efficiency of the hi-tech industry in various provinces and municipalities into the software Geoda and obtains the global Moran's I index of the innovation efficiency of the hi-tech industry in China from 2002 to 2016, as shown in Figure 3. It can be seen that the values of the global Moran's I index of innovation efficiency were all positive during the sample period, and also passed the $10 \%$ or $5 \%$ significance level test, which strongly proves the significant spatial correlation between the innovation efficiency values of the hi-tech industry. At the same time, the results also indicate that the innovation activities in the hi-tech industry in China are not independent of each other, but rather highly spatially correlated, especially in neighbouring provinces and municipalities, where innovation activities have strong spillover effect. In addition, this spatial correlation also proves that the regional innovation efficiency values of the hitech industry are not randomly distributed in space, but rather highly clustered. Therefore, in the analysis of the influencing factors to the innovation efficiency of the hi-tech industry, it is necessary to incorporate this strong spatial correlation into the measurement model; otherwise, ignoring this spatial correlation will most likely cause the conclusion of the study to deviate largely from reality.

Since Figure 3 can only show the overall spatial characteristics of the innovation efficiency of the hi-tech industry in China, to further investigate the local spatial characteristics of the innovation efficiency in various provinces and municipalities, a local scatter plot (LISA) is used, as shown in Figure 4.

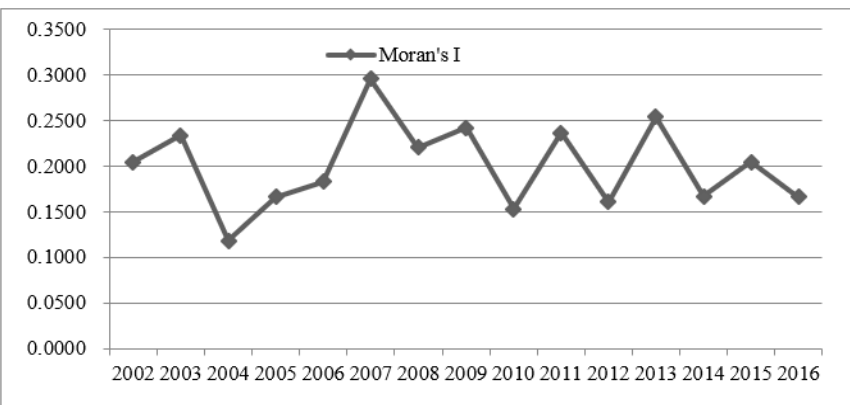

Figure 3. Global Moran's I index of the innovation efficiency of the hi-tech industry in China during 2002-2016

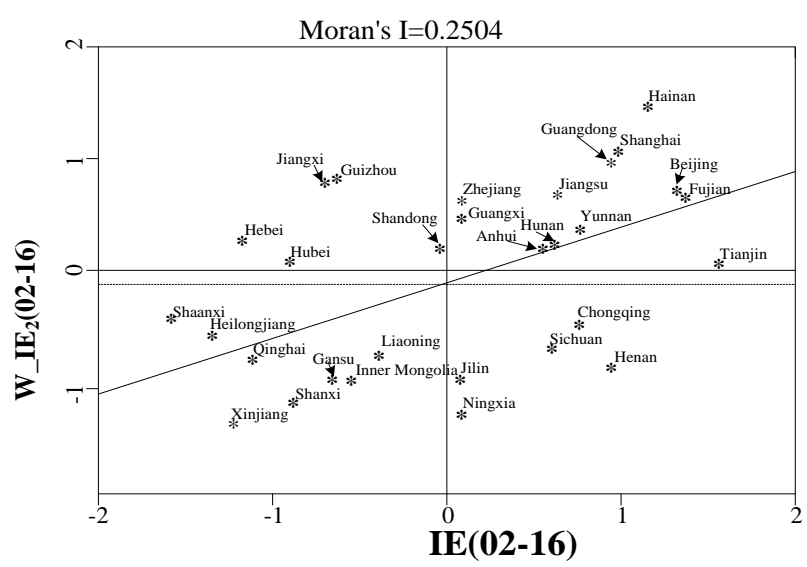

Figure 4. Local scatter plot (LISA) of the innovation efficiency of the hi-tech industry in China during 2002-2016
It is composed of four quadrants, of which the first quadrant $(\mathrm{HH})$ is the high-value cluster area, and the third (LL) is the low-value cluster area, both being typical spatially clustered areas; the second (LH) and the fourth (HL) quadrants are both spatially scattered areas. The provinces and municipalities in the first and third quadrants have high (low) hi-tech industry innovation efficiency, and their neighbouring provinces and municipalities also have high (low) innovation efficiency; and those in the second and fourth quadrants have low (high) innovation efficiency, but their neighbours have high (low) innovation efficiency. Specifically, there are 12 provinces and municipalities in the first quadrant $(\mathrm{HH})$, namely Beijing, Tianjin, Fujian, Hainan, Guangdong, Shanghai, Jiangsu, Yunnan, Hunan, Anhui, Zhejiang and Guangxi, all being typical high-value clustered areas and accounting for $40 \%$ of the total number of provinces and municipalities investigated; there are only 5 provinces and municipalities in the second quadrant (LH), namely Shandong, Hubei, Hebei, Jiangxi and Guizhou, accounting for only 16.67 of the total number; there are 8 provinces and municipalities in the third quadrant $(\mathrm{L}-\mathrm{L})$, namely Liaoning, Inner Mongolia, Gansu, Qinghai, Heilongjiang, Shaanxi, Shanxi and Xinjiang, all being the lowvalue clustered areas and accounting for $26.67 \%$ of the total number; in the fourth quadrant, there are also only 5 provinces and municipalities, namely Jilin, Ningxia, Henan, Chongqing and Sichuan, also accounting for $16.67 \%$ of the total number. In summary, there are as many as 20 provinces and municipalities in the first and third quadrants (spatially clustered areas), taking up $66.67 \%$ of the total number of provinces and municipalities investigated; only 10 provinces and municipalities are in the second and fourth quadrants, accounting for $33.33 \%$. Therefore, it can be seen that most provinces and municipalities in China are located in typical spatially clustered areas, reflecting that the innovation efficiency of the hi-tech industry has a strong spatial clustering feature; but there are also a few provinces and municipalities in the atypical spatially scattered areas, which means the innovation efficiency also has some spatial heterogeneity.

\subsection{Empirical results of the spatial measurement model}

Based on the models (6) and (7) constructed above, this paper first uses the Ordinary Least Square (OLS) method to carry out estimation, and at the same time, in order to verify whether it is necessary to incorporate the spatial effect in the model, Matlab7.11 is further adopted to test the spatial autocorrelation of the residual terms in the model. The specific results are shown in Table 2 . This table concurrently lists the empirical results of four models, namely the model with no fixed effect, the one with spatial fixed effect, the one with time fixed effect and the one with dual fixed effects. By comparing the advantages and disadvantages of the four model results, we can determine whether it is necessary to control the fixed effect in the model.

Table 2 consists of two parts - the upper and the lower parts. The upper part gives the specific test results of the no-fixedeffect model, the spatial fixed effect model, the time fixed effect model and the dual fixed effect model. Firstly, for the four models - no-fixed-effect model, the spatial fixed effect model, the time fixed effect model and the dual fixed effect model, the determination coefficients of goodness of fit are $0.2784,0.0892,0.2832$ and 0.5361 , respectively. It can be seen that compared with the other three models, the dual fixed effect model has the largest determination coefficient of 
goodness of fit, which indicates that the model has the best fit. Secondly, the $\log -L$ values of the four models are compared, among which, the $\log -L$ value of the dual fixed effect model is 128.0496, higher than those of the other three models. Finally, the $D W$ values are also compared. The $D W$ value of the dual fixed effect model is 2.2758 , which is also the largest among the four models. The above comparisons fully show that, whether in terms of the determination coefficient of goodness of fit, the $\log -L$ value or the $D W$ value, the dual fixed effect model is superior to the other three ones; therefore, the estimation results of the dual fixed effect model are optimal. In view of this, this paper selects the results of the dual fixed effect model for variable analysis.

Table 2. Estimation and test results of generic panel data

\begin{tabular}{ccccc}
\hline Variable & No fixed effect & Spatial fixed effect & Time fixed effect & Dual fixed effects \\
\hline$E S$ & $0.0163^{*}$ & -0.0005 & $0.0319^{* * *}$ & -0.0100 \\
& $(1.8477)$ & $(-0.0398)$ & $(2.5933)$ & $(-0.6622)$ \\
$R I$ & 0.0018 & $0.0487^{*}$ & -0.0088 & $0.0407^{*}$ \\
& $(0.0614)$ & $(1.7979)$ & $(-0.3083)$ & $(1.5559)$ \\
$I S$ & $-0.7523^{* * *}$ & 0.0512 & $-0.8460^{* * *}$ & -0.0343 \\
& $(-4.7218)$ & $(0.2162)$ & $(-5.2634)$ & $(-0.1268)$ \\
OP & $0.0905^{* * *}$ & $0.0384^{*}$ & $0.0792^{* * *}$ & $0.0597^{* * *}$ \\
& $(4.3148)$ & $(1.7237)$ & $(3.3587)$ & $(2.5971)$ \\
GI & $-0.4009^{* * *}$ & $-0.1418^{* *}$ & $-0.4219^{* * *}$ & $-0.1125^{*}$ \\
& $(-6.7746)$ & $(-2.3439)$ & $(-7.0031)$ & $(-1.7427)$ \\
HC & 0.1981 & $1.3563^{* * *}$ & 0.0847 & 0.8682 \\
& $(0.8468)$ & $(2.7339)$ & $(0.3693)$ & $(1.4356)$ \\
R-squared & 0.2784 & 0.0892 & 0.2832 & 0.5361 \\
Log- $L$ & 19.7143 & 107.7149 & 38.3548 & 128.0496 \\
DW & 2.0875 & 2.0934 & 2.2726 & 2.2758 \\
LM-lag & $4.0117^{* *}$ & 0.9860 & 0.0142 & $5.1649^{* *}$ \\
Robust LM-lag & $4.6797^{* *}$ & 0.0252 & $16.4898^{* * *}$ & 0.0472 \\
LM-err & $1.9105^{*}$ & 1.0628 & $2.8960^{*}$ & $5.1210^{* *}$ \\
Robust LM-err & $2.5786^{*}$ & 0.1020 & $19.3716^{* * *}$ & 0.0033 \\
\hline
\end{tabular}

Note: the data in brackets are T-test values, *,** and *** represent the significance level of $10 \%, 5 \%$ and $1 \%$, respectively; Matlab7.11 is used for model estimation and spatial auto-correlation test.

The lower part of Table 2 gives the spatial autocorrelation test results of the residual terms in the model. In the dual fixed effect model, the LM-lag value is 5.1649 and passes the 5\% significance level test; the LM-err value is 5.1210, which is also significant at the $5 \%$ level. Both of these indicators reflect that the residual terms of the generic panel model have significant spatial autocorrelation. The ordinary least square (OLS) method cannot solve this problem, and may lead to large errors in the model's estimation results. Therefore, it is necessary to re-estimate the model using a spatial measurement method. Considering that $L M$-lag requires more statistics than $L M$-err, the spatial auto-regressive model $(S A R)$ is a better choice for this study than the spatial error model (SEM).

Table 3. Estimation and test results of the spatial measurement model (dual fixed effect model)

\begin{tabular}{ccc}
\hline Variable & SAR & SEM \\
\hline ES & $-0.0099(-0.6714)$ & $-0.0103(-0.6932)$ \\
RI & $0.0394^{*}(1.5353)$ & $0.0374(1.4510)$ \\
IS & $0.0264(0.0998)$ & $0.0048(0.0177)$ \\
OP & $0.0617^{* * *}(2.7358)$ & $0.0631^{* * *}(2.8166)$ \\
GI & $-0.1089^{*}(-1.7173)$ & $-0.1002^{*}(-1.5872)$ \\
HC & $0.9011^{*}(1.6489)$ & $0.7278(1.2386)$ \\
W*dep. var & $-0.1940^{* * *}(-2.9116)$ & \\
Spat. aut. & & $-0.1880^{* * *}(-2.7950)$ \\
R-squared & 0.5643 & 0.5540 \\
Log-L & 131.2374 & 131.2969 \\
\hline
\end{tabular}

Note: the data in brackets are T-test values, $*, * *$ and $* * *$ represent the significance level of $10 \%, 5 \%$ and $1 \%$, respectively; Matlab7.11 is used for model estimation and spatial auto-correlation test.

Table 3 lists the estimation results of the spatial autoregressive model $(S A R)$ and the spatial error model $(S E M)$. It can be seen that the spatial lagged term $W^{*}$ dep.var is -0.1940 in the spatial auto-regressive model $(S A R)$, and it passes the $1 \%$ significance level test; similarly, the spatial error term $W^{*}$ dep.var is -0.1880 in the spatial error model (SEM), which is also significant at the $1 \%$ level. The above results show that it is reasonable to re-test the models (6) and (7) using the spatial measurement method. At the same time, whether in the spatial auto-regressive model $(S A R)$ or the spatial error model $(S E M)$, not only is the determination coefficient of goodness of fit enlarged on the basis of the conventional model, but the logarithmic likelihood function value $\log -L$ is also optimized. Compared with the estimation results of the conventional model in Table 2, those of the spatial measurement model in Table 3 are much better, improving the accuracy of the entire model. In addition, the determination coefficient of goodness of fit of the spatial auto-regressive model $(S A R)$ is 0.5643 , much larger than that of the spatial error model (SEM) $(0.5540)$, indicating that the estimation results of the spatial auto-regressive model $(S A R)$ are better. In view of this, this paper finally uses the estimation results of the spatial autoregressive model $(S A R)$ to analyze the significance of each explanatory variable.

The estimated coefficient of enterprise size $(E S)$ is negative, but it fails to pass the significance level test, indicating that the expansion of enterprise size cannot effectively improve the innovation efficiency of the hi-tech industry. A possible reason is that it has something to do with the current development of Chinese hi-tech enterprises. Generally speaking, the larger the size of a hi-tech enterprise is, the more capital and manpower it can provide for the innovation activities, and the greater risks it can afford. However, most large-size hi-tech enterprises in China are state-owned enterprises, who are far less sensitive to market than small and medium-sized private enterprises, who 
can explore market opportunities in a timely manner. At the same time, due to the rigid science and technology management system, large-scale hi-tech enterprises have a lower conversion rate of scientific and technological achievements than small and medium-sized private enterprises. In this context, large hi-tech enterprises represented by stateowned enterprises occupy a large share of the market, which is obviously not conducive to enhancing the innovation capabilities of enterprises.

The estimated coefficient of R\&D intensity $(R I)$ is positive and passes the $10 \%$ significance level test, which shows that the increase in the R\&D intensity does improve the innovation efficiency of the hi-tech industry. The greater investment a hitech company makes in its $R \& D$, the more $R \& D$ projects the company will have for new development, the more likely it is for the company to successfully develop a new technology or process, and the more new patents and products it will obtain. The result also shows that, with the rapid development of the hi-tech industry in China, the demand for hi-tech products continues to increase, which raises higher requirements for the R\&D activities in hi-tech enterprises and prompts hi-tech companies to attach greater importance to $R \& D$ investment. The research results of $\mathrm{Gu}$ et al. [34] also confirm that strengthening the $R \& D$ intensity is conducive to improving the innovation performance of small and medium-sized hi-tech enterprises in China.

The estimated coefficient of industrial structure $(I S)$ is positive, but it fails the significance level test, which means that the increase in the proportion of the secondary industry output value in GDP will bring a positive effect on the innovation efficiency of the hi-tech industry, but this effect is not significant. One reason for this is that the proportion of the secondary industry output value in GDP is decreasing. Data show that the output value of the secondary industry in China accounted for $44.5 \%$ of GDP in 2002, and this figure dropped to $39.8 \%$ in 2016 . In addition, although China is taking the new industrialization path, the development of the secondary industry still mainly relies on factor input and external demand stimulation, with generally weak technological innovation capabilities, which determines that the secondary industry is still under an extensive growth model, where the output structure does not match the demand structure. Therefore, China needs to make more effort to improve the development quality of the secondary industry in the future.

The estimated coefficient of opening-up $(O P)$ is positive, and it passes the $1 \%$ significance level test, indicating that the increase in the export delivery value of the hi-tech industry promotes the innovation efficiency of the hi-tech industry. With China opening up further to the outside world, the hi-tech industry is able to participate in the broader international market, which is conducive to increasing the international market demand for technological products, thus stimulating hi-tech enterprises to expand production scale and further strengthen R\&D activities. At the same time, with the export trade of the hi-tech industry continuing to increase, domestic hi-tech enterprises and international leading companies will carry out more technical exchanges, and domestic enterprises will have the opportunities to introduce more advanced production management philosophies and relatively mature technologies so as to support the upgrading of domestic production technologies. Liu and Buck [35] analyzed the effect of international technology spillovers on the innovation efficiency of the hi-tech industry in China, and found that the innovation abilities of domestic enterprises can be improved through import and export trade. Therefore, opening up further to the outside world is a necessary measure to effectively improve the innovation efficiency of the hi-tech industry.

Government intervention $(G S)$ has a negative impact on the innovation efficiency of the hi-tech industry at the significant level of $10 \%$, which means that the higher the proportion of government funds is in the internal $\mathrm{R} \& \mathrm{D}$ cost of the hi-tech industry, the more adverse impact it will have on the innovation efficiency. This result confirms that excessive government funding for R\&D exerts a "crowding-out effect" on its own R\&D investment. The research results of Mamuneas [36] also show that excessive public financial investment in $R \& D$ has an inhibitory effect on the $R \& D$ efficiency.

The estimated coefficient of human capital $(H C)$ is positive, and it passes the $10 \%$ significance level test, indicating that a high proportion of the labour force with education level above high school in the entire labour force is more conducive to improving the innovation efficiency of the hi-tech industry. This result also verifies the previous assumption. At the same time, the result reflects that the level of human capital in a region is the key factor restricting the development of the hitech industry. During the development process of the hi-tech industry, the cultivation of high-quality labour is a more important aspect than capital input that the government should pay attention to in the future.

\section{CONCLUSION}

Improving the innovation efficiency of the hi-tech industry is of great significance to the implementation of the "Made in China 2025" strategy. In order to measure the innovation efficiency of the hi-tech industry in China, this paper establishes an evaluation index system for the innovation efficiency of the hi-tech industry. Then, based on the panel data of 30 provinces and municipalities in China during the period of 2002-2016, this paper uses the CCR model to measure the innovation efficiency of the hi-tech industry in various provinces and municipalities, and at the same time, investigates the spatial correlation of the innovation efficiency of the hi-tech industry, and empirically analyzes the influencing factors to the innovation efficiency of the hi-tech industry using a spatial panel data model. The basic conclusions drawn are as follows:

First, judging from the calculation results, the innovation efficiency of the hi-tech industry in China exhibits significant provincial differences. The hi-tech industry is of high innovation efficiency in the provinces and municipalities in the eastern coastal area, such as Tianjin, Fujian, Beijing, Hainan and Guangdong, which are the top five provinces and municipalities in terms of innovation efficiency; the innovation efficiency of the hi-tech industry is relatively low in the mid-western inland provinces and municipalities, especially in Qinghai, Xinjiang, Heilongjiang and Shaanxi. Although the innovation efficiency of the hi-tech industry in the three major regions of China showed basically the same trend, the regional differentiation was significant - the innovation efficiency of the hi-tech industry was the highest in East China, followed by that in Central China, and the lowest was in West China. This paper calculates the global Moran's I index, which shows that the regional innovation efficiency of the hi-tech industry in China has significant spatial correlation. The spatial LISA chart shows that the innovation efficiency of 
the hi-tech industry in most provinces and municipalities is located in the first $(\mathrm{H}-\mathrm{H})$ and third (L-L) quadrants, which are spatially clustered, while that in only a few provinces and municipalities is located in the second (L-H) and fourth (H-L) quadrants, which are spatially scattered. The results of the spatial panel data model show that the R\&D intensity, opening-up and human capital have positive effects in promoting the innovation efficiency of the hi-tech industry, that government intervention significantly inhibits the improvement of the innovation efficiency and that enterprise size and industrial structure exhibit no significant effects.

\section{ACKNOWLEDGMENT}

This paper was supported by Hebei Science and technology finance Collaborative Innovation Centre / Hebei Science and technology finance key laboratory (No. STFCIC201902).

\section{REFERENCES}

[1] Chakrabarti, A.K. (1991). Competition in high technology: Analysis of patents of US, Japan, UK, France, West Germany, and Canada. IEEE Transactions on Engineering Management, 38(1): 78-84. https://doi.org/10.1109/17.65763

[2] Tseng, F.M., Chiu, Y.J., Chen, J.S. (2009). Measuring business performance in the high-tech manufacturing industry: A case study of Taiwan's large-sized TFT-LCD panel companies. Omega, 37(3): 686-697. https://doi.org/10.1016/j.omega.2007.07.004

[3] Chen, C.J., Huang, C.C. (2004). A multiple criteria evaluation of high-tech industries for the science-based industrial park in Taiwan. Information \& Management, 41(7):

839-851. https://doi.org/10.1016/j.im.2003.02.002

[4] Wang, S., Fan, J., Zhao, D., Wang, S. (2016). Regional innovation environment and innovation efficiency: the Chinese case. Technology Analysis \& Strategic Management, 28(4): 396-410. https://doi.org/10.1080/09537325.2015.1095291

[5] Raab, R.A., Kotamraju, P. (2006). The efficiency of the high-tech economy: Conventional development indexes versus a performance index. Journal of Regional Science, 46(3): 545-562. https://doi.org/10.1111/j.14679787.2006.00452.x

[6] Kocher, M.G., Luptacik, M., Sutter, M. (2006). Measuring productivity of research in economics: A cross-country study using DEA. Socio-Economic Planning Sciences, 40(4): 314-332. https://doi.org/10.1016/j.seps.2005.04.001

[7] Hong, J., Feng, B., Wu, Y., Wang, L. (2016). Do government grants promote innovation efficiency in China's high-tech industries. Technovation, 57: 4-13. https://doi.org/10.1016/j.technovation.2016.06.001

[8] Hsiao, F.S., Park, C. (2005). Korean and Taiwanese productivity performance: comparisons at matched manufacturing levels. Journal of Productivity Analysis, 23(1): 85-107. https://doi.org/10.1007/s11123-0048549-x

[9] Han, C., Thomas, S.R., Yang, M., Ieromonachou, P., Zhang, H. (2017). Evaluating R\&D investment efficiency in China's high-tech industry. The Journal of
High Technology Management Research, 28(1): 93-109. https://doi.org/10.1016/j.hitech.2017.04.007

[10] Chen, X., Liu, Z., Zhu, Q. (2018). Performance evaluation of China's high-tech innovation process: Analysis based on the innovation value chain. Technovation, 74-75: 42-53. https://doi.org/10.1016/j.technovation.2018.02.009

[11] Lee, J., Shim, E. (1995). Moderating effects of R\&D on corporate growth in US and Japanese hi-tech industries: An empirical study. The Journal of High Technology Management Research, 6(2): 179-191. https://doi.org/10.1016/1047-8310(95)90013-6

[12] Guan, J., Chen, K. (2010). Measuring the innovation production process: A cross-region empirical study of China's high-tech innovations. Technovation, 30(5-6): 348-358. https://doi.org/10.1016/j.technovation.2010.02.001

[13] Ketata, I., Sofka, W., Grimpe, C. (2015). The role of internal capabilities and firms' environment for sustainable innovation: Evidence for Germany. R \& D Management, 45(1):

60-75. https://doi.org/10.1111/radm.12052

[14] Erdal, L., Göçer, İ. (2015). The effects of foreign direct investment on R\&D and innovations: Panel data analysis for developing Asian countries. Procedia-Social and Behavioral Sciences, 195(3): 749-758. https://doi.org/10.1016/j.sbspro.2015.06.469

[15] Spencer, B.J., Brander, J.A. (1983). International R \& D rivalry and industrial strategy. The Review of Economic Studies, 50(4): 707-722. https://doi.org/10.2307/2297771

[16] Charnes, A., Cooper, W.W., Rhodes, E. (1978). Measuring the efficiency of decision making units. European Journal of Operational Research, 2(6): 429444.

[17] Qian, L., Wang, W.P., Xiao, R.Q. (2019). Research on China's regional high-tech enterprise innovation efficiency in the perspective of ownership difference. Journal of Industrial Engineering and Engineering Management, 33(2): 99-109. https://doi.org/10.13587/j.cnki.jieem.2019.02.012

[18] Gui, H.B. (2014). Innovation efficiency and its influencing factors of China's high-tech industry based on the spatial econometric model. Economic Geography, 34: 100-107.

[19] Sun, G.F., Zhang, C., Yao, D.W. (2016). The measure of China's large and medium-sized Hi-tech enterprises efficiency and decomposition: An empirical analysis based on DEA model. Journal of Audit \& Economics, 31(03): 111-119.

[20] Zhu, Y.W., Xu, K.N. (2006). The empirical research on R\&D efficiency of Chinese high-tech industries. China Industrial Economy, 11(1): 38-45.

[21] Coe, D.T., Helpman, E. (1995). International R\&D spillover. European Economic Review, 39(5): 859-887. https://doi.org/10.1016/0014-2921(94)00100-E

[22] Fan, Y.Q., Xu, Y.S. (2014). Corruption, government R\&D expenditure and technical innovation efficiency of high-tech industry. Finance and Trade Research, (6): 95102.

[23] Zhuang, T., Wu, H., Hu, C. (2015). Innovation efficiency and impact factors of High-tech industries' UniversityIndustry collaboration: Perspective of triple helix. Finance and Trade Research, 2015(1): 55-60. 
[24] Tobler, W.R. (1979). Philosophy in geography. Theory and Decision Library, 20(1): 379-386.

[25] Moran, P.A. (1948). The interpretation of statistical maps. Journal of the Royal Statistical Society. Series B (Methodological), 10(2): 243-251.

[26] Moran, P.A. (1950). Notes on continuous stochastic phenomena. Biometrika, 37(1/2): 17-23. https://doi.org/10.2307/2332142

[27] Yang, Y.Z., Yang, M. (2019). Research on innovation efficiency and its influencing factors of high-tech industry in two stages -- empirical analysis based on stochastic frontier model. Management Modernization, 2019(5): 37-41. https://doi.org/10.19634/j.cnki.111403/c.2019.05.009

[28] Wang, W., Deng, W.P. (2017). Three-stage innovation efficiency of high-tech industry and its influencing factors-Based on EBM model and Tobit model. Soft Science, 31(11): 16-20. https://doi.org/10.13956/j.ss.1001-8409.2017.11.04

[29] Sandu, S., Ciocanel, B. (2014). Impact of R\&D and innovation on high-tech export. Procedia Economics and Finance, 15: 80-90. https://doi.org/10.1016/S22125671(14)00450-X

[30] Boeing, P. (2016). The allocation and effectiveness of China's R\&D subsidies-evidence from listed firms. Research policy, 45(9): 1774-1789. https://doi.org/10.1016/j.respol.2016.05.007

[31] Nonaka, I., Von Krogh, G., Voelpel, S. (2006). Organizational knowledge creation theory: Evolutionary paths and future advances. Organization Studies, 27(8): 1179-1208. https://doi.org/10.1177/0170840606066312

[32] Anselin, L. (1988). Spatial Econometrics: Methods and Models. Springer Netherlands, 4. https://doi.org/10.1007/978-94-015-7799-1

[33] Haining, R. (1993). Spatial data analysis in the social and environmental sciences. Cambridge University Press.

[34] Gu, Q., Jiang, W., Wang, G.G. (2016). Effects of external and internal sources on innovation performance in Chinese high-tech SMEs: A resource-based perspective. Journal of Engineering and Technology Management, 40: 76-86. https://doi.org/10.1016/j.jengtecman.2016.04.003

[35] Liu, X., Buck, T. (2007). Innovation performance and channels for international technology spillovers: Evidence from Chinese high-tech industries. Research policy, 36(3): 355-366. https://doi.org/10.1016/j.respol.2006.12.003

[36] Mamuneas, T.P. (1999). Spillovers from publicly financed R\&D capital in high-tech industries. International Journal of Industrial Organization, 17(2): 215-239. https://doi.org/10.1016/S0167-7187(97)000398 